\title{
Frontotemporal Network Connectivity during Memory Encoding Is Increased with Aging and Disrupted by Beta-Amyloid
}

\author{
Hwamee $\mathrm{Oh}^{1}$ and William J. Jagust ${ }^{1,2}$ \\ ${ }^{1}$ Helen Wills Neuroscience Institute, University of California, Berkeley, California 94720 and ${ }^{2}$ Life Sciences Division, Lawrence Berkeley National \\ Laboratory, Berkeley, California 94720
}

\begin{abstract}
Approximately $30 \%$ of cognitively normal older adults harbor brain $\beta$-amyloid (A $\beta)$, a prominent feature of Alzheimer's disease associated with neural alterations and episodic memory decline. We examined how aging and $\mathrm{A} \beta$ deposition affect neural function during memory encoding of visual scenes using functional magnetic resonance imaging (fMRI) in humans. Thirty-six cognitively normal older people underwent fMRI scanning, and positron emission tomography with $\left[{ }^{11} \mathrm{C}\right]$ Pittsburgh compound $\mathrm{B}$ to measure fibrillar brain $\mathrm{A} \beta$; 15 young subjects were studied with fMRI. Older adults without $\mathrm{A} \beta$ deposition showed reduced regional brain activation (compared with young subjects) with decreased task-independent functional connectivity between parahippocampal gyrus and prefrontal cortex. In this network, task-related connectivity was increased compared with young subjects, and the degree of connectivity was related to memory performance. In contrast, older individuals with $\mathrm{A} \beta$ deposition showed no such increased task-related network connectivity, but did display increased regional activity unassociated with performance. These findings suggest that network connectivity plays a significant role in compensating for reduced regional activity during successful memory encoding in aging without $\mathrm{A} \beta$ deposition, while in those with $\mathrm{A} \beta$ this network compensation fails and is accompanied by inefficient regional hyperactivation.
\end{abstract}

\section{Introduction}

Advanced age is commonly associated with decline in episodic memory (EM), disruption of regional neural activity, and altered coordination of large-scale brain systems involving the medial temporal lobe (MTL), prefrontal cortex (PFC), parietal cortex, and sensory association cortices that support EM in young adults (Grady et al., 1995; Cabeza et al., 1997; Sperling et al., 2003; Wagner et al., 2005; Dennis et al., 2008; Duverne et al., 2008). When young and older adults perform comparably on EM tasks, studies often find recruitment of additional brain regions, PFC in particular, in older adults, a finding interpreted as compensation for under-recruitment of brain regions normally engaged by young adults such as MTL (Morcom et al., 2003; Gutchess et al., 2005; Dennis et al., 2007). Age-related functional alterations are also found in brain regions that normally display task-related decreases. Compared with young adults, older adults showed aberrant task-related activity increases and functional connectivity reduction across brain regions collectively known as the default

Received June 30, 2013; revised 0ct. 10, 2013; accepted 0ct. 12, 2013.

Author contributions: H.O. and W.J. designed research; H.O. and W.J. performed research; H.O. analyzed data; H.O. and W.J. wrote the paper.

This research was supported by the National Institute on Aging (Grant number AG034570) and the Alzheimer's Association. We thank two anonymous reviewers for their helpful comments and Elizabeth Mormino for the assistance with behavioral data analysis.

The authors declare no competing financial interests.

Correspondence should be addressed to Dr. Hwame Oh, 132 Barker Hall MC \#3190, University of California, Berkeley, CA 94720-3190. E-mail: hwameeoh@berkeley.edu.

DOI:10.1523/JNEUROSCI.2775-13.2013

Copyright $\odot 2013$ the authors $\quad 0270-6474 / 13 / 3318425-13 \$ 15.00 / 0$ mode network (DMN), which is engaged during the resting state and deactivated during externally driven cognitive processes (Lustig et al., 2003; Andrews-Hanna et al., 2007). Considering the involvement of the DMN in memory retrieval processes (Buckner et al., 2008; Daselaar et al., 2009), age-related disruption in the DMN suggests a close relationship between EM decline and age-related alterations in task-induced deactivation and temporal synchrony in brain activation across regions.

Recent studies using Pittsburg compound B (PIB)-positron emission tomography (PET) have detected pathological neural alterations before clinically evident cognitive decline. One of these pathological changes is accumulation of $\beta$-amyloid (A $\beta)$, a hallmark of Alzheimer's disease (AD) that is commonly found in normal older people (Bennett et al., 2006; Mintun et al., 2006). Recent studies using PET to image fibrillar forms of $A \beta$ show that its accumulation leads to structural and functional changes well before clinically evident decline is apparent (Perrin et al., 2009). Studies examining functional changes in relation to $\mathrm{A} \beta$ pathology have found that the regional topography of $A \beta$ deposition and the DMN are largely overlapping and that functional connectivity across brain regions in the DMN is significantly reduced in older people with amyloid deposition (Buckner et al., 2005). Importantly, while age-related aberrant activation was noted in the DMN during the resting state and in task-positive brain regions during a task, the degree of dysfunction in regional activity, in posterior cingulate/precuneus and MTL in particular, was exacerbated in elderly subjects with higher $A \beta$ deposition (Sperling et al., 2009; Vannini et al., 2013). However, it remains unknown whether and how age and $\mathrm{A} \beta$ deposition affect functional con- 
Table 1. Characteristics of participants

\begin{tabular}{|c|c|c|c|}
\hline & Young & $\mathrm{PIB}-0 \mathrm{LD}$ & $\mathrm{PIB}+0 \mathrm{LD} *$ \\
\hline$N$ & 15 & 23 & 13 \\
\hline Age, year & $23.2 \pm 3.6(20-30)$ & $75.6 \pm 6.0(65-91)$ & $76.8 \pm 8.2(66-97)$ \\
\hline Education, year & $15.6 \pm 1.7(14-20)$ & $17.3 \pm 2.1(12-20)$ & $16.9 \pm 2.1(13-20)$ \\
\hline Gender, $n, \mathrm{~F} / \mathrm{M}^{a}$ & $7 / 8$ & $14 / 9$ & $8 / 5$ \\
\hline PIB index & $1.01 \pm 0.03^{b}$ & $1.02 \pm 0.04(0.8-1.07)$ & $1.29 \pm 0.2(1.08-1.8)$ \\
\hline APOE- $\epsilon 4, n(\%)^{c}$ & $\mathrm{n} / \mathrm{a}$ & $6(29 \%)$ & $9(67 \%)$ \\
\hline Recognition ${ }^{d}$ & $0.57 \pm 0.26$ & $0.55 \pm 0.25$ & $0.38 \pm 0.25$ \\
\hline $\mathrm{Hit}^{e}$ & $0.62 \pm 0.11$ & $0.64 \pm 0.12$ & $0.61 \pm 0.15$ \\
\hline Misses $^{e}$ & $0.38 \pm 0.11$ & $0.36 \pm 0.12$ & $0.39 \pm 0.15$ \\
\hline False alarms ${ }^{e}$ & $0.40 \pm 0.14$ & $0.43 \pm 0.09$ & $0.47 \pm 0.18$ \\
\hline MMSE & $28.4 \pm 1.5(26-30)$ & $29.2 \pm 1.0(25-30)$ & $29 \pm 1.2(25-30)$ \\
\hline
\end{tabular}

Values are presented as mean $\pm S D$ (range). ${ }^{a} \chi^{2}=1.21, p>0.5 .{ }^{b}$ PIB index calculated from 11 young subjects who underwent PIB-PET. PProportion of individuals with ApoE genotypes $\epsilon 3 / 4$ or $\epsilon 4 / 4, \chi^{2}=4.9, p<0.05$. ApoE genotypes of two PIB - older subjects were not available. ${ }^{d}$ Discriminability index, D-prime scores, representing recognition accuracy rates corrected for false positive rates, $F_{(2,48)}=2.56, p>0.05$. ${ }^{e}$ Rates of each measure combining high and low confidence. * ${ }^{*}$ lassified as PIB + if PIB index was greater than mean +2 SD of the PIB index of young adults. The resulting cutoff score was 1.08 .

nectivity in brain regions supporting EM while subjects are engaged in a task. In the present study, we aimed to dissociate the effect of age and $A \beta$ deposition on regional brain activity and functional connectivity during memory encoding in normal older people. Based on these previous results, we hypothesized that regional activity in the MTL and visual association areas would decrease with advanced age, but increase with $\mathrm{A} \beta$ deposition and that task-related functional connectivity would be reduced by $\mathrm{A} \beta$ deposition.

\section{Materials and Methods}

Participants. Fifteen healthy young (mean age $=23.2$ years, 7 females) and 36 cognitively normal older adults (mean age $=76.2$ years, 22 females) were included in the present study. Older adults were additionally classified as either PIB positive (PIB+ OLD) or PIB negative (PIBOLD) based on the criteria described below. All subjects underwent functional magnetic resonance imaging (fMRI) and structural MRI scans and all older subjects completed PET scans using the radiotracer $\left[{ }^{11} \mathrm{C}\right] \mathrm{PIB}$. In addition, all older subjects underwent a medical interview and a detailed battery of neuropsychological tests. To be eligible for the study, older subjects were required to be 60 years or older, live independently in the community without neurological or psychiatric illness, and have no major medical illness or medication that influenced cognition. Apolipoprotein $\mathrm{E}$ (ApoE) $\varepsilon 4$ carrier status was determined for most older subjects using previously published methods (Agosta et al., 2009). All subjects provided informed consent in accordance with the Institutional Review Boards of the University of California, Berkeley, and the Lawrence Berkeley National Laboratory (LBNL).

Experimental design. During the fMRI acquisition, participants performed an incidental episodic encoding task, which has been described in detail previously (Mormino et al., 2012a). Subjects in this study were a subset of those in our previous report (Mormino et al., 2012a) who passed more stringent criteria for minimal head motion (i.e., within-run motion smaller than $0.5 \mathrm{~mm}$ in translation and 0.5 degree in rotation; Friston et al., 1996). Briefly, participants were presented pictures of scenes one by one at the center of the screen over four functional runs. Each scene image was presented for $4.4 \mathrm{~s}$ with a varying intertrial interval (mean $3.46 \mathrm{~s}$, range $=0-11 \mathrm{~s}$ ). Subjects were instructed to indicate whether there was water or no water on each image by button press. A total of 200 trials ( 50 trials per run) were completed by subjects.

After the scan, subjects were given a surprise memory task in which they made a recognition judgment for each scene, indicating whether or not they had seen the scene previously in the experiment (new or old), and their level of confidence (high or low) in their decision. Presentations of scenes were classified as encoding trials to model hemodynamic responses, and categorized into three different trial types based on the recognition response to the presentation of each scene during the recognition task: (1) scenes subsequently remembered with high confidence
(HC-HIT); (2) scenes subsequently remembered with low confidence (LC-HIT); and (3) scenes subsequently forgotten (MISS), collapsed across high and low confidence to obtain sufficient numbers of trials. In addition, encoding trials with no response for water judgment during the encoding task were separately modeled.

Individuals' recognition memory performance was calculated as a discriminability index using D-prime scores, which represent the proportion of hit rates corrected for false positive rates, combining high and low confidence ratings (Snodgrass and Corwin, 1988).

PIB-PET acquisition, image processing and analysis. Detailed information on PET data acquisition and image processing is provided in a previous report (Mormino et al., 2012a). Briefly, $\left[{ }^{11} \mathrm{C}\right]$ PIB was synthesized at LBNL's Biomedical Isotope Facility using a previously published protocol (Mathis et al., 2003). All PET scans were performed at LBNL using a Siemens ECAT EXACT HR PET scanner in 3D acquisition mode. Dynamic acquisition frames were obtained over $90 \mathrm{~min}$ following injection of $10-15 \mathrm{mCi}$ of $\left[{ }^{11} \mathrm{C}\right] \mathrm{PIB}$.

All PET images were preprocessed using Statistical Parametric Mapping 8 (SPM8; http://www.fil.ion.ucl.ac.uk/spm/). Region of Interest (ROI) labeling was implemented using the FreeSurfer v4.5 software package (http://surfer.nmr.mgh.harvard.edu/) to create a reference region in the gray matter of the cerebellum and to perform subsequent ROI analyses. A PIB distribution volume ratio (DVR) was calculated using Logan graphical analysis and a gray matter-masked cerebellar reference region with frames corresponding to 35-90 min postinjection (Logan et al., 1996; Price et al., 2005).

A global PIB index representing overall $\mathrm{A} \beta$ deposition across the brain was calculated in each subject's native space using DVR values across frontal (all frontal regions anterior to the precentral sulcus), temporal (superior and middle temporal gyri), parietal (superior and inferior parietal cortices, supramarginal gyrus, and precuneus), and anterior/ posterior cingulate cortices. These large ROIs were created using FreeSurfer-generated anatomical ROIs in each subject's native space. Older adults were classified PIB + OLD if their whole-brain PIB uptake (or PIB index) was $>2$ SDs above the mean of a group of young adults (Mormino et al., 2012b). Thirteen older subjects fell above this threshold of 1.08 and were classified as PIB + with 23 as PIB-.

$f M R I$ data acquisition. Whole-brain images were acquired using a Siemens 1.5T Magnetom Avanto System (Siemens Medical Systems) at LBNL. High-resolution anatomical images were acquired with a T1weighted volumetric magnetization prepared rapid gradient echo sequence $($ repetition time $(\mathrm{TR})=2110 \mathrm{~ms}$; echo time $(\mathrm{TE})=3.58 \mathrm{~ms}$; flip angle $(\mathrm{FA})=15^{\circ}$; field of view $\left.(\mathrm{FOV})=256 \times 256 \mathrm{~mm}\right)$. A T1-weighted in-plane anatomical volume of 28 axial slices was acquired (TR $=591 \mathrm{~ms}$, $\mathrm{TE}=10 \mathrm{~ms}, \mathrm{FA}=150^{\circ}, \mathrm{FOV}=220 \times 220 \mathrm{~mm}$, slice thickness $=3.4$ $\mathrm{mm}$ ). For the task runs, volumes of functional images were acquired using a $2^{\star}$-weighted gradient-echo echoplanar images sequence (TR $=$ $2200 \mathrm{~ms} ; \mathrm{TE}=50 \mathrm{~ms}$; flip angle $\left.=90^{\circ} ; \mathrm{FOV}=220 \times 220 \mathrm{~mm}\right)$. Each functional volume consisted of 28 axial slices in the same orientation as the in-plane images. Six dummy volumes were acquired at the beginning of each functional run to allow the MR signal to reach equilibrium; these images were discarded from the dataset before image processing and analysis.

fMRI image processing and analysis. All preprocessing and statistical analyses were conducted using SPM8 (Wellcome Department of Cognitive Neurology, London, UK). Functional images were corrected for differences in slice timing. Head motion was corrected using a 6-parameter rigid body correction to realign each image to the first volume of the middle run. In-plane and high-resolution images were segmented into gray and white matter and coregistered with the mean functional image. Images were then normalized to the Montreal Neurological Institute (MNI) gray matter template brain using a 12-parameter affine registration followed by nonlinear transformations (Friston et al., 1995). Last, images were smoothed with a Gaussian kernel of $8 \mathrm{~mm}$ at a full-width at half-maximum.

For the whole-brain analysis, we used the general linear model (GLM) to construct a design matrix for each individual dataset. fMRI trials were classified into four conditions (i.e., HC-HIT, LC-HIT, MISS, and no water response trials). We defined the onset times of stimulus presenta- 


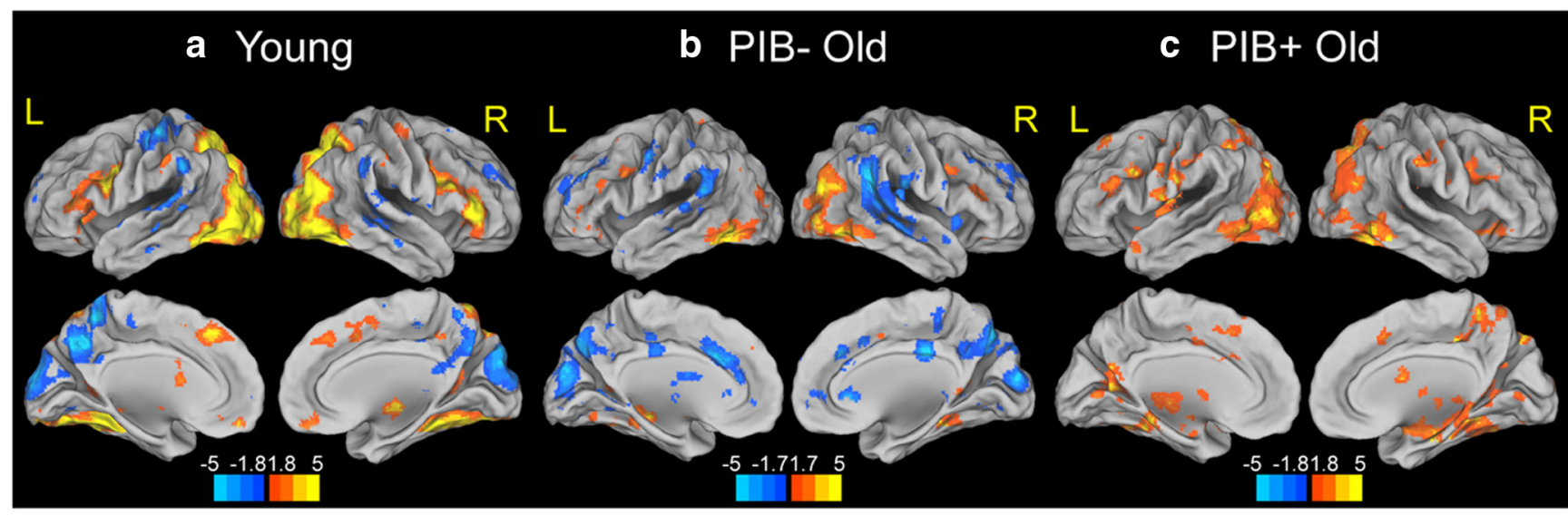

Figure 1. Brain activity for successfully encoded (HC-HIT) versus forgotten items (MISS) in young (a), PIB - OLD (b), and PIB + OLD (c) groups. Suprathreshold regions are overlaid on the inflated cortical surface in MNI space. The color scale represents $t$ values with warm colors indicating significantly increased activity for successfully encoded items compared with forgotten items (HC-HIT $>$ MISS) and cool colors indicating an opposite pattern (MISS $>$ HC-HIT) in each group. Maps show suprathreshold regions significant at $p<0.05$ voxel level, with FDR correction at $p<0.05$ at cluster level for multiple comparisons across the whole-brain volume. L, left hemisphere; $R$, right hemisphere.

tion and modeled them with a canonical hemodynamic response function (HRF) with duration of $4.4 \mathrm{~s}$. Six motion regressors were included in the design matrix as covariates of no interest to take into account of subject motion. Scan volumes for which motion parameters combining translation and rotation measures exceed $0.5 \mathrm{~mm}$ were additionally covaried out in the analysis (i.e., scrubbing) to minimize any motionrelated artifacts in both regional activity and functional connectivity results (Power et al., 2012; Van Dijk et al., 2012; Wilke, 2012).

Estimated parameters ( $\beta$-values) of each condition were derived for each individual using the GLM described above (i.e., first-level analysis). The $t$ tests were applied at the group level for comparing and contrasting task conditions and groups (i.e., second-level analysis). For within-group one-sample $t$ tests and group contrasts between PIB- OLD and PIB+ OLD groups, age was added as a covariate of no interest. Unless otherwise stated, a threshold of $p<0.05$ uncorrected at the voxel level and a false discovery rate (FDR) correction of $p<0.05$ at the cluster level were used to interpret the whole-brain results.

Functional connectivity analyses. We applied psychophysiological interaction (PPI) analysis (Friston et al., 1997; Gitelman et al., 2003) to examine functional coupling between the MTL and other brain areas during the HC-HIT compared with the MISS condition. Connectivity maps were produced using a GLM with an initiating seed in the right parahippocampal gyrus (rPHG). We used rPHG as a seed, because of its involvement in visual episodic encoding and the relevance of PHG to visual scene processing (Epstein and Kanwisher, 1998; Prince et al., 2009). The rPHG was defined on the task-based contrast (i.e., HC-HIT $>$ MISS). This seed was used to define whole-brain task-independent connectivity and the PPI, the latter of which is an interaction between the time course of the rPHG seed and the task-based regressor (Friston et al., 1997; Gitelman et al., 2003). This interaction identifies voxels that are temporally synchronous in a task-dependent manner (i.e., stronger temporal synchrony for HC-HIT than MISS conditions). Coordinates of the rPHG seed region were determined individually and guided by group mean coordinates $(x=28, y=-34, z=-16)$ when more than one peak region within rPHG was present. For each individual, we used the HCHIT versus MISS contrast at an uncorrected threshold of $p<0.05$ to find the suprathreshold voxel nearest to the peak coordinate of the group within the rPHG AAL anatomical mask (Tzourio-Mazoyer et al., 2002). Volumes of interest (VOI) were defined as spheres with $6 \mathrm{~mm}$ radius.

At the subject level, a GLM for PPI analysis included the time course of the rPHG seed (i.e., the physiological component), a task-based regressor (i.e., the psychological component corresponding to HC-HIT vs MISS), and an interaction term of the cross-product (i.e., the PPI term) between the psychological component and time course of the seed. The physiological component was extracted for the VOI, corrected for variance associated with parameters of no interest (e.g., motion regressors), and deconvolved with the HRF. The psychological component was generated by convolving the contrast of the HC-HIT versus MISS with the HRF. The PPI component was derived by reconvolving the multiplication of the deconvolved physiological component and psychological component with the HRF. The PPI, the physiological component, and the psychological component were used as predictors of interest and six motion regressors were included in this GLM model as nuisance variables to account for effects of subject motion.

Estimated parameters ( $\beta$-values) of each regressor were derived for each individual using the PPI GLM described above (i.e., first-level analysis). To test group differences for PPI connectivity (i.e., brain regions showing increased coupling with the rPHG at encoding for HC-HIT compared with MISS, as assessed by the PPI regressor) and temporal connectivity (i.e., brain regions showing temporal synchrony with the rPHG activity regardless of task conditions, as assessed by the physiological regressor), twp-sample $t$ tests were applied at the group level for the PPI regressor and the physiological regressor (i.e., second-level analysis). Unless otherwise stated, a threshold of $p<0.05$ uncorrected at the voxel level and $p<0.05$ FDR corrected at the cluster level for multiple comparisons were used to assess the whole-brain results.

Linking recognition performance and PPI connectivity. To explore the functional significance of regional activity and PPI functional connectivity in relation to recognition performance, mean parameter estimates from brain regions showing age and $\mathrm{A} \beta$-related changes in regional activity and PPI functional connectivity were extracted from suprathreshold voxels from group contrasts between young, PIBOLD, and PIB + OLD groups using the MarsBaR MATLAB toolbox (Brett et al., 2002; http://marsbar.courceforge.net). These values were then used in further regression analyses with recognition index (i.e., D-prime scores) using SPSS v.20. Age and sex were controlled in the regression model.

\section{Results}

\section{Subject characteristics}

Subject data are summarized in Table 1 . PIB + versus PIBgroups did not differ on measures such as age, gender, education, and Mini Mental State Examination (MMSE). The PIB+ group, however, had significantly more ApoE e4 carriers than the PIBgroup $\left(\chi^{2}=4.9, p<0.05\right)$. Across all subjects, recognition performance, measured as a discriminability index using D-prime scores, on the post scan memory testing did not differ across groups ( $p s>0.1)$. No significant difference was found with rates of hits, misses, and false alarms across groups, either ( $p s>0.5$ ). 
Table 2. Peak coordinates of subsequently remembered (HC-HIT) versus forgotten (MISS) contrasts within group and group contrast

\begin{tabular}{|c|c|c|c|c|c|}
\hline Cluster size & $x$ & $Y$ & $Z$ & $T$ values & Regions \\
\hline \multicolumn{6}{|c|}{ Young subjects } \\
\hline \multicolumn{6}{|c|}{ HC-HIT > MISS } \\
\hline \multirow[t]{2}{*}{9708} & -48 & -56 & -16 & 14.06 & Left inferior temporal gyrus \\
\hline & -28 & -74 & 34 & 9.98 & Left middle occipital gyrus \\
\hline \multirow[t]{2}{*}{9276} & 28 & -66 & 48 & 9.55 & Right angular gyrus \\
\hline & 26 & -62 & 56 & 8.37 & Right superior parietal lobule \\
\hline \multirow{2}{*}{4631} & 26 & -14 & 0 & 7.32 & Right inferior frontal gyrus \\
\hline & 48 & 36 & 8 & 6.5 & Right inferior frontal gyrus \\
\hline \multirow[t]{3}{*}{4136} & -38 & 14 & 22 & 6.1 & Left inferior frontal gyrus \\
\hline & -32 & 20 & 22 & 6 & Left inferior frontal gyrus \\
\hline & -40 & 2 & 32 & 5.75 & Left precentral gyrus \\
\hline 1227 & -4 & 32 & 46 & 4.66 & Left superior medial gyrus \\
\hline \multirow{2}{*}{6392} & -6 & -50 & 58 & 6.33 & Left precuneus \\
\hline & 2 & -94 & 16 & 6.04 & Left cuneus \\
\hline \multirow[t]{3}{*}{1544} & -66 & -38 & 16 & 5.05 & Left superior temporal gyrus \\
\hline & -64 & -42 & 38 & 4.68 & Left superior temporal gyrus \\
\hline & -58 & -66 & 6 & 4.45 & Left middle temporal gyrus \\
\hline \multirow[t]{3}{*}{2203} & 46 & -30 & -10 & 4.77 & Left middle temporal gyrus \\
\hline & 56 & -24 & -14 & 4.7 & Right middle temporal gyrus \\
\hline & 54 & -30 & 12 & 4.6 & Right superior temporal gyrus \\
\hline \multirow[t]{3}{*}{$414^{*}$} & -40 & -30 & -4 & 4.24 & Left middle temporal gyrus \\
\hline & -50 & -24 & -14 & 3.97 & Left middle temporal gyrus \\
\hline & -46 & -24 & -6 & 3.66 & Left middle temporal gyrus \\
\hline $387^{*}$ & 4 & -30 & 46 & 3.88 & Right middle cingulate cortex \\
\hline 2527 & -48 & -54 & -18 & 7.09 & Left inferior temporal gyrus \\
\hline & -48 & -62 & -10 & 5.37 & Left inferior temporal gyrus \\
\hline & -26 & -26 & -12 & 5.33 & Left hippocampus \\
\hline 2562 & 42 & -82 & -6 & 5.88 & Right inferior occipital gyrus \\
\hline & 42 & -80 & 20 & 4.74 & Right middle occipital gyrus \\
\hline & 50 & -58 & -12 & 4.72 & Right inferior temporal gyrus \\
\hline 655 & -36 & 34 & -10 & 5.12 & Left inferior frontal gyrus \\
\hline & -34 & 26 & 14 & 2.82 & Left inferior frontal gyrus \\
\hline & -18 & 28 & 20 & 2.72 & Left inferior frontal gyrus \\
\hline 576 & 56 & 36 & 16 & 3.21 & Right inferior frontal gyrus \\
\hline & 50 & 30 & 16 & 2.94 & Right inferior frontal gyrus \\
\hline & 38 & 8 & 32 & 2.83 & Right inferior frontal gyrus \\
\hline MISS $>\mathrm{HC}$ & & & & & \\
\hline 3523 & -12 & 18 & 32 & 5.45 & Left middle frontal gyrus \\
\hline & -32 & 46 & 32 & 4.21 & Left middle frontal gyrus \\
\hline & 10 & 36 & 30 & 4.21 & Right middle cingulate cortex \\
\hline 929 & 4 & -24 & 32 & 5.27 & Right middle cingulate cortex \\
\hline & 0 & -20 & 44 & 3.31 & Left middle cingulate cortex \\
\hline & 10 & -32 & 56 & 3.18 & Right paracentral lobule \\
\hline 10553 & 56 & -46 & 28 & 5.15 & Right supramarginal gyrus \\
\hline & 4 & -90 & 16 & 5.06 & Left cuneus \\
\hline & -4 & -74 & 32 & 5.05 & Left cuneus \\
\hline 1002 & -62 & -44 & 20 & 4.57 & Left superior temporal gyrus \\
\hline & -66 & -30 & 8 & 4.07 & $\begin{array}{l}\text { Left middle temporal gyrus } \\
\text { (Table continues.) }\end{array}$ \\
\hline
\end{tabular}


Table 2. Continued

\begin{tabular}{|c|c|c|c|c|c|}
\hline Cluster size & $x$ & $Y$ & $Z$ & $T$ values & Regions \\
\hline & -66 & -26 & 16 & 3.52 & Left middle temporal gyrus \\
\hline \multirow[t]{2}{*}{$206^{*}$} & 38 & -48 & 66 & 4.41 & Right superior parietal lobule \\
\hline & 26 & -56 & 60 & 1.95 & Right superior parietal lobule \\
\hline \multirow[t]{3}{*}{574} & -26 & 8 & 4 & 4.36 & Left putamen \\
\hline & -20 & 18 & 4 & 3.46 & Left putamen \\
\hline & -24 & -2 & 16 & 2.99 & Left putamen \\
\hline \multirow[t]{3}{*}{503} & -54 & -8 & 44 & 4.26 & Left postcentral gyrus \\
\hline & -58 & -16 & 32 & 3.16 & Left postcentral gyrus \\
\hline & -58 & -4 & 36 & 2.82 & Left postcentral gyrus \\
\hline \multirow[t]{3}{*}{$477^{*}$} & 4 & 32 & 2 & 4.11 & Anterior cingulate cortex \\
\hline & 24 & 16 & -4 & 3.54 & Right putamen \\
\hline & 14 & 54 & 2 & 2.88 & Right superior medial gyrus \\
\hline \multirow[t]{3}{*}{1134} & -26 & -64 & 6 & 4.02 & Left calcarine gyrus \\
\hline & -38 & -54 & 6 & 3.11 & Left calcarine gyrus \\
\hline & 4 & -32 & -6 & 3.04 & Periaqueductal gray \\
\hline \multirow[t]{3}{*}{$425^{*}$} & -10 & -6 & 4 & 3.44 & Left thalamus \\
\hline & -8 & 0 & 16 & 3.02 & Left caudate nucleus \\
\hline & -12 & -6 & 32 & 2.85 & Left middle cingulate cortex \\
\hline \multirow[t]{3}{*}{$238^{*}$} & 40 & 14 & 0 & 3.33 & Right insula lobe \\
\hline & 56 & 8 & -18 & 2.88 & Right medial temporal pole \\
\hline & 54 & 8 & -6 & 1.91 & Right temporal pole \\
\hline \multicolumn{6}{|c|}{ PIB + 0LD subjects } \\
\hline \multicolumn{6}{|c|}{ HC-HIT > MISS } \\
\hline \multirow[t]{3}{*}{21711} & 52 & -44 & -14 & 7.05 & Right inferior temporal gyrus \\
\hline & 20 & -8 & -18 & 6.97 & Right hippocampus \\
\hline & 54 & -54 & -10 & 6.89 & Right inferior temporal gyrus \\
\hline \multirow[t]{3}{*}{3817} & -56 & 10 & 38 & 5.39 & Left precentral gyrus \\
\hline & -36 & 18 & 28 & 4.99 & Left inferior frontal gyrus \\
\hline & -60 & -14 & 26 & 4.73 & Left postcentral gyrus \\
\hline \multirow[t]{3}{*}{1016} & 30 & 12 & 36 & 3.66 & Right inferior frontal gyrus \\
\hline & 48 & 4 & 28 & 3.46 & Right precentral gyrus \\
\hline & 44 & 14 & 16 & 3.44 & Right inferior frontal gyrus \\
\hline \multicolumn{6}{|c|}{ Young $>$ PIB $-0 L D$} \\
\hline \multirow[t]{3}{*}{7050} & -24 & -66 & 42 & 6.71 & Left inferior parietal lobule \\
\hline & -30 & -84 & 26 & 6.63 & Left middle occipital gyrus \\
\hline & -26 & -76 & 36 & 6.1 & Left middle occipital gyrus \\
\hline \multirow[t]{3}{*}{10678} & 46 & 34 & 4 & 6.25 & Right inferior frontal gyrus \\
\hline & 34 & -74 & 22 & 5.38 & Right middle occipital gyrus \\
\hline & 42 & -2 & 34 & 5.35 & Right precentral gyrus \\
\hline \multirow[t]{3}{*}{4796} & -38 & 10 & 22 & 5.45 & Left inferior frontal gyrus \\
\hline & -18 & 14 & 38 & 4.39 & Left inferior frontal gyrus \\
\hline & -26 & 8 & 4 & 4.2 & Left putamen \\
\hline Young $<1$ & & & & & \\
\hline 912 & 12 & -92 & 32 & 4.11 & Right cuneus \\
\hline & -4 & -92 & 28 & 3.72 & Left cuneus \\
\hline & -2 & -98 & 8 & 3.55 & Left calcarine gyrus \\
\hline 970 & -34 & -22 & 54 & 3.75 & Left precentral gyrus \\
\hline & -24 & -42 & 60 & 3.37 & Left postcentral gyrus \\
\hline & -4 & -46 & 66 & 2.92 & Left precuneus \\
\hline $\mathrm{PIB}+0 \mathrm{LD}$ & & & & & \\
\hline 5563 & -24 & 0 & 18 & 4.71 & Left precentral gyrus \\
\hline & -26 & -12 & 46 & 4.37 & Left postcentral gyrus \\
\hline & -8 & 22 & 30 & 4.35 & Left anterior cingulate cortex \\
\hline 11012 & 48 & -36 & 14 & 3.94 & Right superior temporal gyrus \\
\hline & 30 & -74 & 18 & 3.86 & Right superior occipital gyrus \\
\hline & 44 & -30 & -6 & 3.83 & Right inferior temporal gyrus \\
\hline 1254 & -58 & -4 & 36 & 3.91 & Left postcentral gyrus \\
\hline & -60 & -14 & 30 & 3.55 & Left postcentral gyrus \\
\hline & -52 & -10 & 42 & 2.85 & Left postcentral gyrus \\
\hline
\end{tabular}

*Clusters that were significant at the cluster level, but did not survive multiple-comparison correction.

Age and $\mathrm{A} \boldsymbol{\beta}$ deposition differentially influence regional brain activation for successful encoding

First, we examined brain regions associated with successful encoding (contrast HC-HIT vs MISS) across participants within each group (Fig. 1, Table 2). For young adults, successful encoding was associated with greater activity in lateral frontal and parietal cortices, bilaterally, and visual association (VA) areas spanning lateral occipital cortices and ventral temporal cortices 


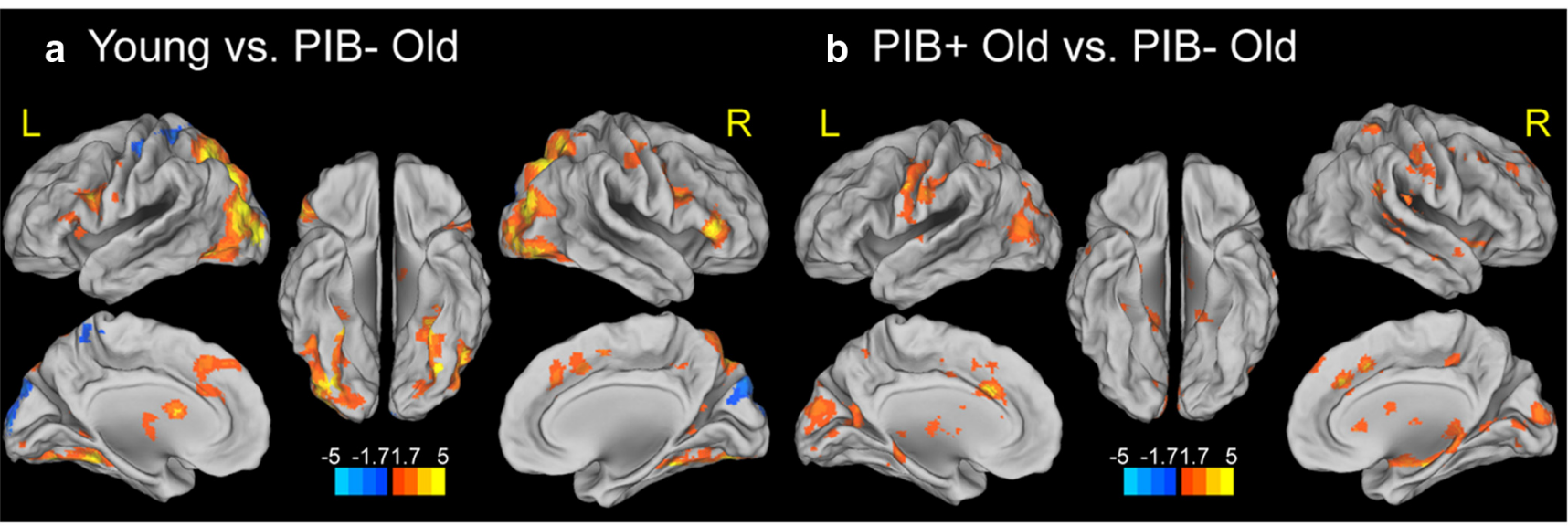

Figure 2. Effects of age and A $\beta$ deposition on brain activity for successfully encoded (HC-HIT) versus forgotten items (MISS). $\boldsymbol{a}$, Age-related differences in brain activity for successfully encoded versus forgotten items. Suprathreshold regions are overlaid on the inflated cortical surface in MNI space. The color scale represents $t$ values with warm colors indicating significantly increased activity in young subjects compared with PIB - OLD for successfully encoded items compared with forgotten items. $\boldsymbol{b}, \mathrm{A} \beta$ deposition shows greater brain activity for HC-HIT than MISS conditions. Suprathreshold regions are overlaid on the inflated cortical surface in MNI space. The color scale represents $t$ values with warm colors indicating significantly increased activity in PIB +0 LD compared with PIB - OLD for successfully encoded items compared with forgotten items. No region shows significantly increased activity in PIB - OLD compared with PIB + OLD adults in the same contrast. Maps show suprathreshold regions significant at $p<0.05$ voxel level, with FDR correction at $p<0.05$ at cluster level for multiple comparisons across the whole-brain volume. L, left hemisphere; R, right hemisphere.

including fusiform gyrus and PHG, bilaterally. Among subcortical regions, greater activity in bilateral hippocampus, left caudate and putamen, and right thalamus was shown. On the other hand, significantly decreased activity for successful encoding compared with forgotten trials was found in precuneus, cuneus, superior and middle temporal gyrus, and lateral parietal cortex, bilaterally. Within PIB - OLD, successful encoding was associated with significantly increased activations in posterior brain regions including inferior temporal gyrus, fusiform gyrus, inferior and middle occipital gyrus, and PHG, and the inferior frontal gyrus, bilaterally. Significantly increased activity was also found in hippocampus bilaterally. Similar to young adults, successful encoding was accompanied by significantly decreased activity compared with forgotten trials in precuneus, cuneus, superior and middle temporal gyrus, lateral parietal cortex, bilaterally as well as middle cingulate cortex. Within PIB + OLD, significantly increased activations in association with successful encoding were found in the lateral frontal and parietal cortices, bilaterally, VA areas including lateral inferior temporal cortex, fusiform gyrus, and PHG, bilaterally, and anterior cingulate cortex. Greater activity was also observed in subcortical regions including hippocampus bilaterally, right caudate, and thalamus bilaterally. No voxels, however, showed significantly decreased activity for successful encoding. Across all groups, inferior temporal cortices, ventral temporal cortices spanning fusiform gyrus and PHG, hippocampus bilaterally, and inferior and middle occipital cortices bilaterally, and bilateral frontal cortex showed increased successful encoding activations.

Next we examined age and $A \beta$-related differences in activation for successful encoding. By comparing young and PIBolder adults, a significant age-related decrease in activation for successful encoding was found in left inferior parietal cortex, middle occipital gyrus bilaterally, right inferior and middle frontal gyri, and left putamen. A significant age-related increase in activation for successful encoding was found in cuneus bilaterally, left calcarine gyrus, and left pre/postcentral gyrus, and left precuneus (Fig. 2a, Table 2). For comparisons between PIBOLD and PIB + OLD, A $\beta$-related increases in activation during successful encoding were found in the right hippocampus, left anterior cingulate cortex, right middle cingulate cortex, right middle frontal cortex, lateral parietal and occipital cortex, pre/ postcentral gyrus bilaterally, right lingual gyrus, calcarine gyrus bilaterally, putamen, and thalamus bilaterally. No suprathreshold voxels were found with the opposite contrast (Fig. 2b, Table 2).

\section{Age and $\mathrm{A} \boldsymbol{\beta}$ deposition differentially influence memory encoding-related PPI connectivity}

First, we identified age-related differences in functional connectivity by examining the PPI between the rPHG and other brain regions that show stronger temporal synchrony for HC-HIT than MISS. Comparing young and PIB - older adults, a significant age-related increase in PPI connectivity was found in inferior frontal gyrus bilaterally, left pre/postcentral gyrus, left caudate and putamen, and right anterior cingulate cortex $(p<0.05$, at the cluster level, corrected for multiple comparisons). No suprathreshold voxel was found with the opposite contrast (Fig. 3a). Next, we examined A $\beta$-related differences in PPI functional connectivity. Compared with PIB - OLD, PIB + OLD showed lower PPI connectivity between the rPHG and other brain regions including the left fusiform gyrus, middle occipital gyrus bilaterally, right superior parietal lobule, right middle frontal gyrus, left superior medial gyrus, and left pallidum (Fig. $3 b$ ). A detailed list of peak coordinates showing significant age and $\mathrm{A} \beta$ effects on encoding-related PPI connectivity with the $\mathrm{PHG}$ is provided in Table 3.

\section{Stronger PPI connectivity is associated with better recognition performance in older adults without $A \beta$ deposition}

We examined whether age and $\mathrm{A} \beta$-related differential activity and connectivity relate to individual differences in recognition performance in older adults. We conducted two multiple regressions using parameter estimates of suprathreshold clusters identified by the regional activity and PPI connectivity contrast between YOUNG and PIB- OLD (i.e., parameter estimates averaged over all suprathreshold voxels in Figs. $2 a$ and $3 a$, respectively) as predictors with recognition performance as the depen- 


\section{a PIB- Old vs. Young}
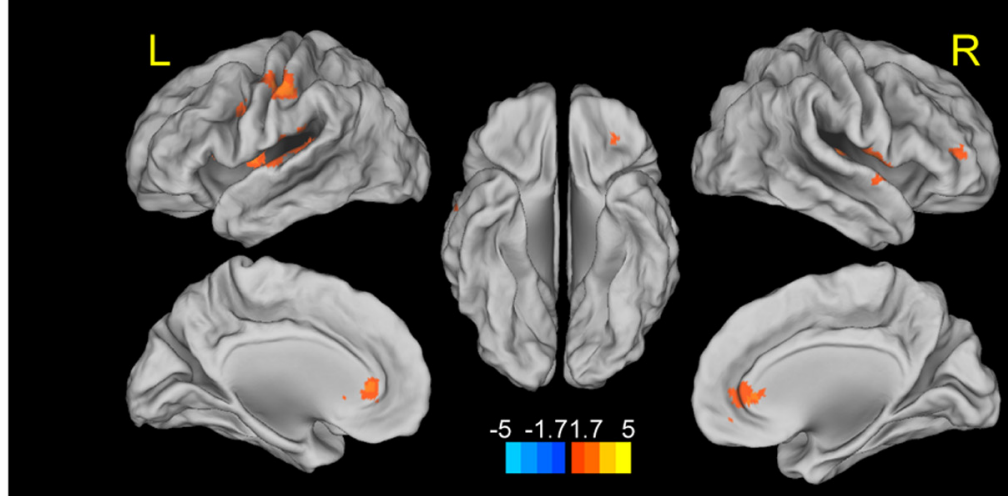

b PIB- Old vs. PIB+ Old
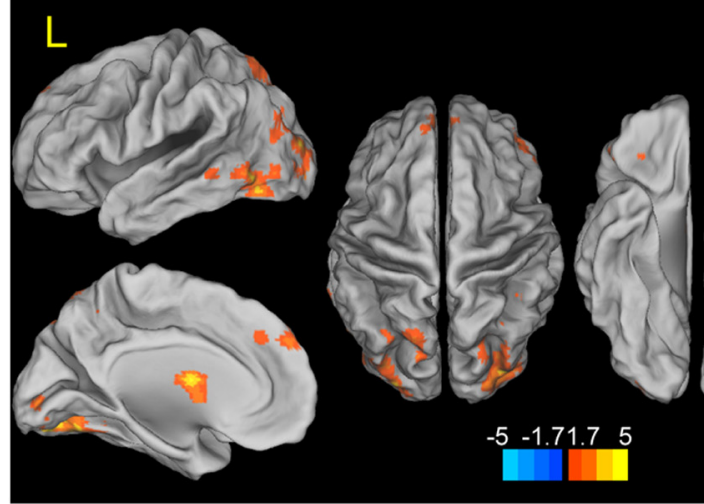

Figure 3. Effects of age and $A \beta$ deposition on PPI connectivity representing stronger coupling for successfully encoded than forgotten items. $\boldsymbol{a}$, Stronger connectivity between $\mathrm{PPHG}$ and PFC in PIB - OLD than YOUNG during successful memory encoding (HC-HIT vs MISS conditions). Suprathreshold regions are overlaid on the inflated cortical surface in MNI space. The color scale represents $t$ values with warm colors indicating significantly stronger connectivity between rPHG and medial and lateral PFC in PIB - OLD compared with YOUNG. No region shows significantly stronger connectivity with the PPHG seed region in YOUNG compared with PIB - OLD adults. $\boldsymbol{b}$, Stronger connectivity between $\mathrm{PPHG}$ and PFC and VA in PIB - OLD than PIB + OLD during successful memory encoding (HC-HIT vs MISS conditions). Suprathreshold regions are overlaid on the inflated cortical surface in MNI space. The color scale represents $t$ values with warm colors indicating significantly stronger connectivity between the rPHG and other voxels. No region shows significantly stronger connectivity with the $\mathrm{rPHG}$ seed region in PIB + OLD compared with PIB $-0 \mathrm{LD}$ adults. Maps show suprathreshold regions significant at $p<0.05$ voxel level, with FDR correction at $p<0.05$ at cluster level for multiple comparisons across the whole-brain volume. L, left hemisphere; $R$, right hemisphere.

dent measure. Age and sex were added in each model as covariates. As depicted in Figure $4 a$, the degree of PPI connectivity between $\mathrm{rPHG}$ and other brain regions was positively related to recognition performance in older, PIB - individuals $(\beta=0.44$, $p<0.05)$. The regional activity in brain regions showing agerelated decreases, however, was not related to recognition performance $(\beta=-0.05, p>0.5$; Fig. $4 b)$.

Next, we assessed the association between recognition performance and regional activity and PPI connectivity of brain regions showing an $\mathrm{A} \beta$ effect in $\mathrm{PIB}+$ older adults. Using a similar multiple regression model, parameter estimates of suprathreshold clusters identified by the regional activity and PPI connectivity contrast between PIB - OLD and PIB + OLD (i.e., parameter estimates averaged over all suprathreshold voxels in Fig. $2 b$ and Fig. $3 b$, respectively) were included as predictors with recognition performance as the dependent measure. Neither PPI connectivity (Fig. 4c) nor regional activity (Fig. $4 d$ ) was associated with recognition performance in PIB + OLD adults.
$\mathrm{R}$

\section{Task-independent time course}

connectivity decreases with advanced age Given the age-related increases in taskdependent functional connectivity between rPHG and PFC in the present study, we examined whether task-independent functional connectivity in our sample replicates previous findings showing age-related decreases in functional connectivity mainly obtained during the resting state (Damoiseaux et al., 2008). To assess temporal synchrony between the rPHG and other brain regions independent of the task main effect (as measured by the psychological term) and interaction (as measured by the PPI term), mean time course functional connectivity maps were generated based on the time series regressor of the rPHG seeds by age group. When we assessed the age effect on the temporal connectivity, young adults, compared with PIB - OLD, showed stronger temporal connectivity of the rPHG with frontoparietal regions spanning the bilateral middle and inferior PFC, anterior cingulate, and precentral cortices, as well as bilateral parietal cortices, precuneus, and occipital cortex (Fig. 5). No suprathreshold voxel was found with the opposite contrast. When we examined the effect of $A \beta$ deposition on the connectivity, no differences were seen between PIB + OLD and PIB- OLD. A detailed list of peak coordinates showing a significant age-effect on temporal connectivity with the rPHG is provided in Table 3.

\section{Effect of ApoE genotype}

To explore the possible influence of ApoE genotypes on the observed relationships between $\mathrm{A} \beta$ deposition and regional brain activity and functional connectivity, we conducted whole-brain analyses using multiple regressions with $\mathrm{PIB}$ group membership (PIB + vs PIB - OLD), ApoE genotype (ApoE4 carriers vs noncarriers), and an interaction term of PIB group and ApoE genotype, as predictors of interest. Contrast maps (i.e., HC-HIT vs MISS) and PPI connectivity maps were used as dependent measures for regional activity and functional connectivity analyses, respectively. Age was added as a nuisance covariate. In the whole-brain analysis on PPI connectivity, we found a significant interaction between PIB group and ApoE4 status mostly in posterior brain regions including the precuneus and temporoparietal cortices bilaterally, which is depicted in cool colors in Figure $6 a$. For regional activity, a significant interaction between PIB group and ApoE4 status was found in the right inferior frontal gyrus and precentral gyrus, which is depicted in cool colors in Figure $6 b$. These regions showing an interaction between PIB group and ApoE status, however, did not overlap with the regions showing significant associations with PIB status for both PPI connectivity and regional activity measures as identified by separate GLMs described previously and depicted in Figures $2 b$ and $3 b$. For comparison purposes, the regions identified in Figures $2 b$ 
Table 3. Peak coordinates of group differences in PPI functional connectivity and task-independent connectivity with the right PHG and other brain regions

\begin{tabular}{|c|c|c|c|c|c|}
\hline Cluster size & $x$ & $Y$ & $Z$ & $T$ values & Regions \\
\hline \multicolumn{6}{|c|}{ PPI functional connectivity } \\
\hline \multicolumn{6}{|c|}{ PIB $-0 L D>$ Young } \\
\hline \multirow[t]{3}{*}{1248} & -8 & 32 & 2 & 4.02 & Left anterior cingulate cortex \\
\hline & -14 & 18 & 4 & 2.62 & Left caudate nucleus \\
\hline & 8 & 42 & 0 & 2.38 & Right anterior cingulate cortex \\
\hline \multirow[t]{3}{*}{1042} & -50 & -22 & 44 & 3.89 & Left postcentral gyrus \\
\hline & -62 & -14 & 42 & 2.84 & Left postcentral gyrus \\
\hline & -42 & 2 & 30 & 2.46 & Left precentral gyrus \\
\hline \multirow[t]{3}{*}{1709} & -28 & -4 & 2 & 3.63 & Left putamen \\
\hline & -42 & -24 & 20 & 3.46 & Left rolandic operculum \\
\hline & -18 & -12 & 16 & 3.13 & Left caudate nucleus \\
\hline \multirow[t]{3}{*}{642} & 52 & 2 & 6 & 2.87 & Right rolandic operculum \\
\hline & 48 & -20 & 8 & 2.68 & Right Heschl's gyrus \\
\hline & 56 & 4 & -4 & 2.35 & Right temporal pole \\
\hline \multicolumn{6}{|c|}{$P I B-0 L D>P I B+0 L D$} \\
\hline \multirow[t]{3}{*}{4015} & -24 & -78 & -10 & 4.52 & Left fusiform gyrus \\
\hline & -28 & -94 & 12 & 4.21 & Left middle occipital gyrus \\
\hline & -32 & -84 & 30 & 3.81 & Left middle occipital gyrus \\
\hline \multirow[t]{3}{*}{899} & -4 & -2 & 12 & 4.28 & Left caudate nucleus \\
\hline & -26 & -6 & -2 & 3.56 & Left pallidum \\
\hline & -6 & 2 & 2 & 3.31 & Left caudate nucleus \\
\hline \multirow[t]{3}{*}{1811} & 38 & -78 & 18 & 3.77 & Right middle occipital gyrus \\
\hline & 32 & -86 & 6 & 3.24 & Right middle occipital gyrus \\
\hline & 26 & -76 & 52 & 3.15 & Right superior parietal lobule \\
\hline \multirow[t]{3}{*}{875} & 32 & 46 & -4 & 3.27 & Right middle frontal gyrus \\
\hline & 38 & 48 & 10 & 3.18 & Right middle frontal gyrus \\
\hline & 46 & 50 & 4 & 2.98 & Right middle frontal gyrus \\
\hline \multirow[t]{3}{*}{845} & -4 & 54 & 36 & 2.94 & Left superior medial gyrus \\
\hline & 2 & 36 & 32 & 2.93 & Left superior medial gyrus \\
\hline & -8 & 46 & 34 & 2.88 & Left superior medial gyrus \\
\hline \multicolumn{6}{|c|}{ Task-independent connectivity } \\
\hline \multicolumn{6}{|c|}{ Young $>$ PIB $-0 \mathrm{LD}$} \\
\hline \multirow[t]{3}{*}{1698} & 32 & -2 & 52 & 5 & Right middle frontal gyrus \\
\hline & 42 & 12 & 22 & 4.46 & Right inferior frontal gyrus \\
\hline & 56 & 14 & 34 & 4.23 & Right inferior frontal gyrus \\
\hline \multirow[t]{3}{*}{1090} & 0 & 12 & 32 & 4.7 & Left middle cingulate cortex \\
\hline & 10 & 28 & 30 & 4.58 & Right middle cingulate cortex \\
\hline & 4 & 2 & 50 & 4.57 & Right supplementary motor area \\
\hline \multirow[t]{3}{*}{1168} & 26 & -80 & 38 & 4.61 & Right superior occipital gyrus \\
\hline & 14 & -72 & 38 & 3.84 & Right cuneus \\
\hline & 40 & -76 & 26 & 3.69 & Right middle occipital gyrus \\
\hline \multirow[t]{3}{*}{3597} & -26 & -68 & 44 & 4.59 & Left inferior parietal lobule \\
\hline & -28 & -36 & 46 & 4.46 & Left postcentral gyrus \\
\hline & -28 & -84 & 30 & 4.41 & Left middle occipital gyrus \\
\hline
\end{tabular}

and $3 b$ are overlaid as warm colored regions in Figure $6 a$ and $b$, respectively.

Using a two-way ANOVA with $\beta$-values from the suprathreshold regions showing an interaction between PIB group and ApoE4 status (i.e., brain regions depicted in cool colors in Fig. $6 a, b)$ and a main effect of PIB group (i.e., brain regions depicted in warm colors in Fig. $6 a, b)$, ROI analyses further confirmed regional dissociations between brain regions showing a significant interaction between PIB group and ApoE4 status and a main effect of $\mathrm{A} \beta$ deposition. For brain regions showing an interaction on functional connectivity, no main effect of PIB group was found, $F=0.81, p=0.37$, but a main effect of ApoE4 status and an interaction were significant: ApoE4 status, $F=14.68, p<$ 0.001 ; PIB group ${ }^{\star}$ ApoE4, $F=18.16, p<0.001$ (Fig. $6 c$, left). Brain regions showing the main effect of $\mathrm{A} \beta$ deposition on PPI connectivity, however, showed neither effect of ApoE genotype nor interaction with PIB group membership: PIB group, $F=$ 7.42, $p=0.01$; ApoE4 status, $F=3.03, p>0.05$; PIB group *
ApoE4, $F=0.01, p=0.94$ (Fig. $6 c$, right). A similar pattern of results was found with regional activity data. For brain regions showing an interaction on regional activity, only the interaction between PIB group and ApoE genotype was significant, but no significant main effect of PIB group and ApoE genotype was found: PIB group, $F=1.36, p=0.25$; ApoE4 status, $F=1.26, p=$ 0.30 ; PIB group ${ }^{\star}$ ApoE4, $F=9.22, p=0.005$ (Fig. $6 d$, left). Brain regions showing the effect of $\mathrm{A} \beta$ deposition on regional activity, however, revealed only the significant main effect of PIB group, but neither effect of ApoE genotype nor interaction with PIB group membership: PIB group, $F=16.58, p<0.001$; ApoE4 status, $F=0.28, p=0.76$; PIB group * ApoE4, $F=0.01, p=0.93$ (Fig. $6 d$, right).

\section{Discussion}

In this study we examined how age and fibrillar $\mathrm{A} \beta$ deposition affect regional activity, functional connectivity (both task dependent and task independent) and behavior. Several key findings 
a

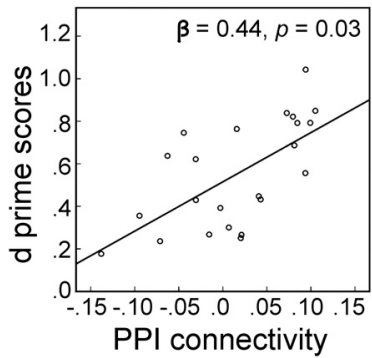

C

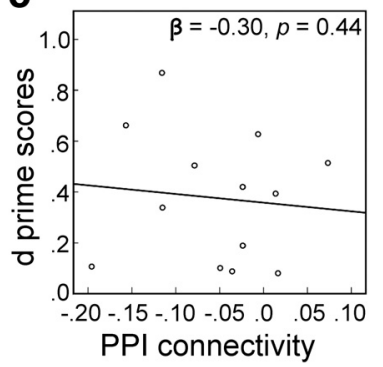

b

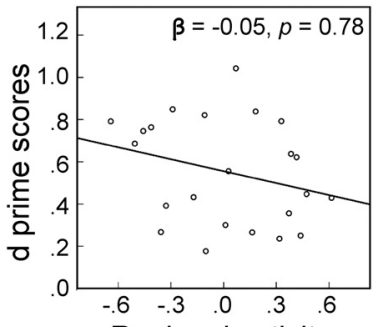

Regional activity

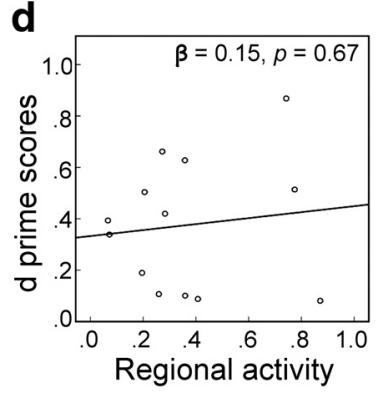

Figure 4. Association between recognition accuracy and differential brain activity for PIB$0 \mathrm{LD}$ and PIB + OLD. $\boldsymbol{a}, \operatorname{In}$ PIB $-0 \mathrm{LD}$, better recognition accuracy was related to stronger PPI connectivity between regions that showed an age-related increase in PPI connectivity as depicted in Figure $3 a$. A scatterplot illustrates the positive relationship between recognition accuracy and averaged parameter estimates of clusters showing significantly stronger PPI connectivity in PIB - OLD than young subjects during successful memory encoding. The relationship between recognition accuracy and parameter estimates was statistically significant, $\beta=0.44, p<0.05$, controlling for age and sex. $\boldsymbol{b}$, The regressions between regional brain activity showing age-related decreases, as depicted in Figure $2 a$, and recognition accuracy, however, were not significant $(\beta=-0.05, p>0.5)$, controlling for age and sex. $\boldsymbol{c}, \boldsymbol{d}, \operatorname{In} \mathrm{PIB}+$ $0 L D$, recognition accuracy was not related to either PPI connectivity in brain regions showing $A \beta$-related reduction as illustrated in Figure $3 b(\beta=-0.30, p>0.4)$ or brain activity in regions showing an $A \beta$-related increase in regional activity, as illustrated in Figure $2 b(\beta=$ $0.15, p>0.5)$, controlling for age and sex.

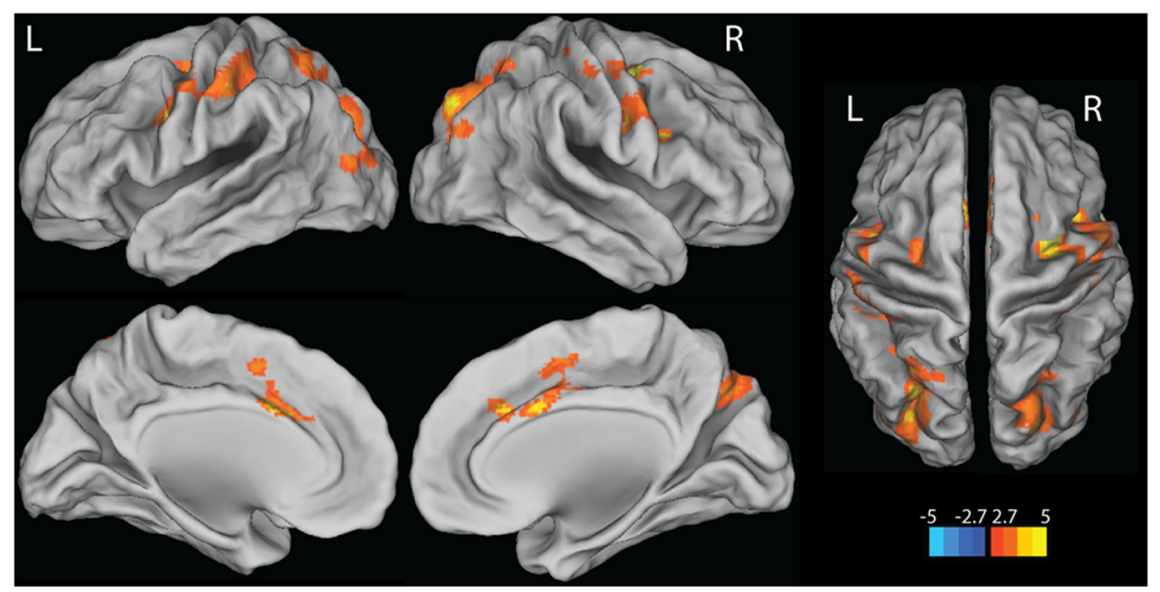

Figure 5. Stronger task-independent functional connectivity between $\mathrm{PPHG}$ and other brain regions in YOUNG than PIB $-0 \mathrm{LD}$. Suprathreshold regions are overlaid on the inflated cortical surface in MNI space. The color scale represents $t$ values with warm colors indicating significantly stronger task-independent functional connectivity between rPHG and lateral PFC, anterior cingulate, lateral parietal cortices, and precuneus in YOUNG compared with PIB -0 LD. No region shows significantly stronger connectivity with the rPHG seed region in PIB - OLD adults compared with YOUNG. Maps show only suprathreshold regions significant at $p<$ 0.005 voxel level, with FDR correction at $p<0.05$ at cluster level. L, left hemisphere; $R$, right hemisphere.

emerged: (1) we replicated findings of age-related decreases and $\mathrm{A} \beta$-related increases in activations in brain regions implicated in successful episodic encoding (Gutchess et al., 2005; Sperling et al., 2009), (2) we found that older adults exhibited greater task-

dependent functional connectivity while experiencing agerelated decreases in regional activity and task-independent connectivity, (3) this age-related increase in task-dependent functional connectivity was present only in older adults who do not harbor $\mathrm{A} \beta$ deposition and was associated with better recognition performance. None of these findings were explained by ApoE genotype.

\section{Effects of age}

Age-related decreases in regional activity during episodic encoding are often found in the posterior brain regions that are specialized for processing visual information (Grady et al., 1999; Gutchess et al., 2005; Dennis et al., 2008). In contrast, age-related increases are often reported in PFC, which is interpreted as a compensatory mechanism for reduced activity in posterior brain regions (Dennis et al., 2008; Spreng et al., 2010). Our findings extend these previous results by showing that with equivalent performance in episodic encoding, age is associated with decreased regional activity in posterior VA and MTL even in individuals who do not show evidence of $A \beta$ deposition. In addition, task-independent functional connectivity was reduced in aging, consistent with reports of resting-state functional connectivity (Achard and Bullmore, 2007; Damoiseaux et al., 2008; Grady et al., 2010).

Considering the importance of PFC and MTL interactions in memory shown in both animal and human studies (Simons and Spiers, 2003), age effects on functional connectivity during memory have been investigated particularly between these regions (Cabeza et al., 1997; Grady et al., 2003; Daselaar et al., 2006; Dennis et al., 2008). We found that, compared with young adults, PIB - older adults exhibited stronger connectivity for successful encoding between the rPHG and the lateral frontal cortices, the right anterior middle frontal gyrus in particular, in the presence of age-related decreases in task-independent functional connectivity. The anterior part of middle frontal gyrus has been considered as a part of the dorsal attention network and implicated in top-down control processes (Vincent et al., 2008). More importantly, this increased task-dependent functional connectivity was further associated with individual differences in recognition performance in PIB - older adults, which is consistent with previous reports in young adults showing that top-down modulation exerted by the engagement of PFC on the posterior VA areas and MTL relates to better performance in working memory with visual scenes (Gazzaley et al., 2007) and episodic encoding (Dickerson et al., 2007). Therefore, our findings of agerelated increases in task-related frontotemporal functional connectivity provide strong evidence for a compensatory mechanism by demonstrating both age-related differences in neural function without performance differences, and associations with individual differences in behavior among the older group (Grady, 2012).

\section{Effects of fibrillar $A \boldsymbol{\beta}$}

In patients with $\mathrm{AD}$ and Mild Cognitive Impairment (MCI), aberrant increases in activity, particularly in the MTL, have been 
observed compared with controls (Dickerson et al., 2005). Our whole-brain analyses confirm our previously reported ROI analysis (Mormino et al., 2012a) showing greater brain activation in multiple regions in older people with brain $\mathrm{A} \beta$. These findings are also consistent with other studies showing that, compared with normal controls, mildly symptomatic MCI patients show greater activity in taskpositive regions identified by the facename association task while activity in these regions decreases in more severely affected MCI and AD patients (Celone et al., 2006). It is important to note that regional activity increases in PIB + OLD in the present study were observed by comparing group differences between two task conditions (HC-HIT vs MISS; D'Esposito et al., 2003) rather than task-related activity compared with baseline; the latter could result in aberrant increases in blood oxygenation level-dependent fMRI signal due to $A \beta$-related baseline changes in cerebral blood flow or neurovascular coupling (Iadecola, 2004; Bangen et al., 2009; Fleisher et al., 2009).

Over-recruitment of brain activity in cognitively normal older adults has been widely reported across different types of cognitive processes and includes a form of frontal overactivation in the presence of reduced activation in posterior brain regions (e.g., posterior-anterior shift in aging; PASA; Dennis and Cabeza, 2008) or reduced lateralized activation (e.g., the HAROLD model; Cabeza, 2002). By excluding PIB + older adults, we found age-related reduction in brain activity for successful encoding, with $\mathrm{A} \beta$-related increases in brain activation. However, we cannot definitively interpret our results as suggesting that previous age-related overactivation reports reflect $\mathrm{A} \beta$ deposition because many different factors (including task, specific contrast, and thresholds) can affect results. While in some studies the increased activation was associated with better performance (Grady et al., 2005), the lack of association between activation and performance does not lead to a clear interpretation of the findings in our data.

The $\mathrm{A} \beta$-related reduction in task-related coupling between rPHG and other brain regions is consistent with results from transgenic mouse models showing that pathologically elevated $\mathrm{A} \beta$ induces aberrant neuronal activity (Busche et al., 2008, 2012), reduced connectivity (Bero et al., 2012), and increased asynchrony (Palop and Mucke, 2010; Roberson et al., 2011) and from human neuroimaging studies showing reduced functional connectivity associated with $\mathrm{A} \beta$ deposition during the resting state (Sorg et al., 2007; Hedden et al., 2009; Sheline et al., 2010a). Our findings extend previous studies by showing that $A \beta$ deposition disrupts not only resting-state functional connectivity of the DMN but also task-dependent functional connectivity of brain regions engaged in EM encoding, the modulation of which is beneficial for recognition performance as shown in amyloidnegative older adults. Thus, our findings provide further evidence that $\mathrm{A} \beta$ deposition is related to brain disconnection in many ways, especially between the MTL and the neocortex (Greicius et al., 2004; Buckner et al., 2005).

Our findings were not explained by the well known association between $\mathrm{A} \beta$ deposition and the ApoE4 allele, a genotype also associated with alterations in connectivity and brain activation (Bookheimer et al., 2000; Filippini et al., 2009; Sheline et al., 2010b; Westlye et al., 2011; Damoiseaux et al., 2012). However, we did detect interactions between ApoE genotype and $\mathrm{A} \beta$ on both connectivity and activation in a different constellation of brain regions than the ones that showed the main $\mathrm{A} \beta$ effect. These findings are consistent with other reports that ApoE genotype and $\mathrm{A} \beta$ may exert independent effects on brain function (Jagust et al., 2012).

Greater task-related regional activity in association with diminished task-dependent functional connectivity in PIB + subjects has alternative explanations. One possibility is that the primary dysfunction is greater regional activity reflecting $A \beta$ related destabilized neural activity that in turn results in network desynchronization. Alternatively, the regional increase in activity may be a compensatory mechanism for the reduced connectivity across brain regions, although the lack of association between activation and performance militates against this interpretation. These alternatives are, however, not mutually exclusive; greater neural activity could be both a primary result of $A \beta$ deposition and a response to network failure. A hypothetical model of relationships between age, $\mathrm{A} \beta$ deposition, regional activity, task- 


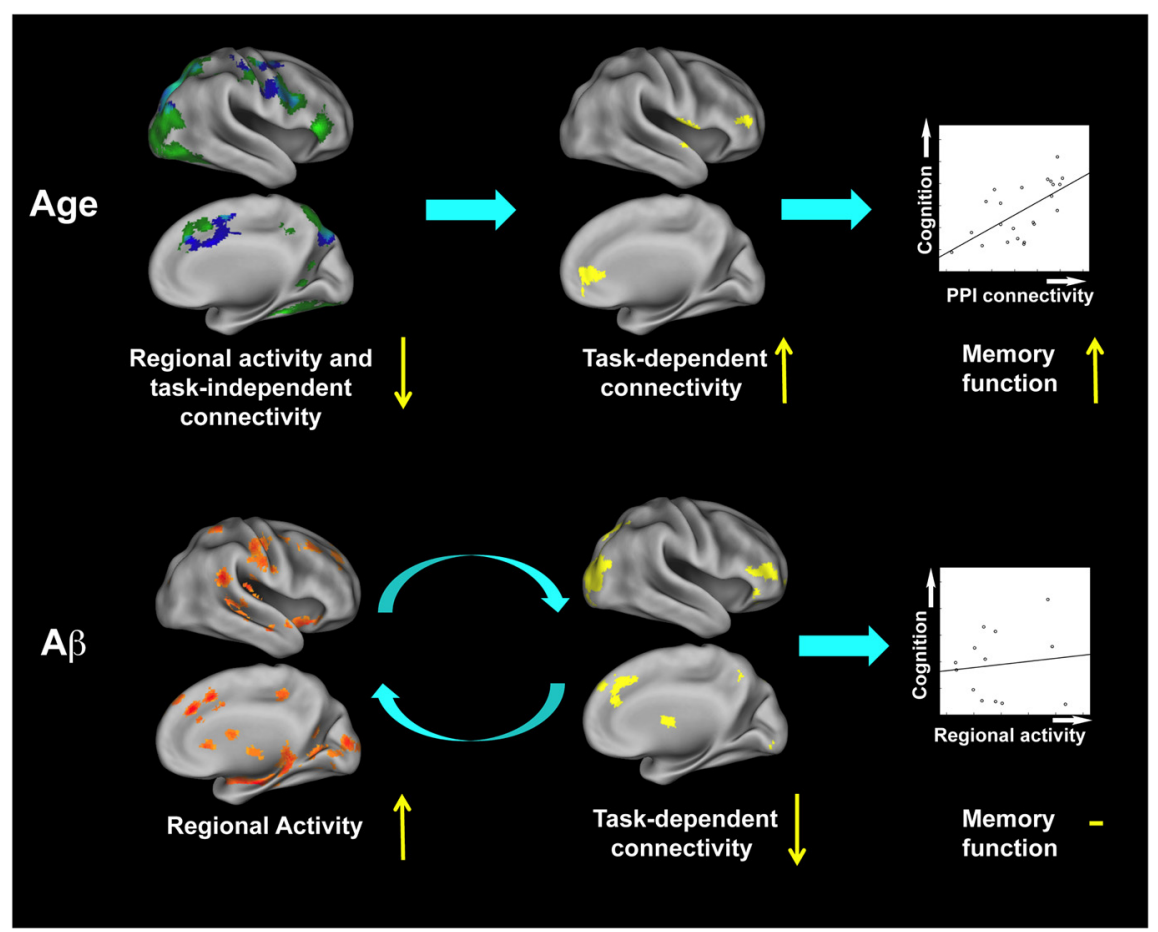

Figure 7. Relationships between age, $A \beta$ deposition, brain function, and cognition. Each brain image represents the projection of data from Figures 2, 3, and 5 onto the inflated cortical surface of the right hemisphere along with brain function and behavior relationships as shown in Figure $4 a$, and $d$. The present findings suggest differential age and $A \beta$-related changes in regional activity and MTL-seeded connectivity during episodic encoding. Age (in the absence of $A \beta$ ) is associated with failure to engage brain regions crucial to encoding new information, such as MTL structures, and also with reduced task-independent connectivity across brain regions. These changes are accompanied by increased task-dependent functional connectivity contributing to preserved EM performance in older adults. Elevated $A \beta$ deposition, on the other hand, recruits more local activity in conjunction with the failure to engage task-dependent functional coupling to perform EM encoding equivalently to older adults without $A \beta$ deposition. This increased regional activity is not associated with memory function. Increased regional activity and taskindependent connectivity for YOUNG compared with PIB - OLD are shown in green and blue, respectively, while the overlapping regions are shown in cyan; increased task-dependent connectivity for PIB - OLD compared with either YOUNG or PIB + OLD are shown in yellow; increased regional activity for PIB + OLD compared with PIB - OLD is shown in orange/red.

independent and task-dependent connectivity, and recognition performance are summarized in Figure 7 . Together the findings suggest that aging is associated with reduced regional activity and task-independent coupling, which is compensated by behaviorally relevant increases in task-dependent connectivity for successful memory encoding. Individuals with $A \beta$, however, fail to show increases in task-related connectivity but demonstrate greater regional activity. Whether these functional alterations reflect incipient $\mathrm{AD}$ remains to be established, but their presence appears consistent with neural failure.

\section{Limitations of the present study}

We found no overall behavioral differences in recognition of visual scenes across groups. The lack of age-related difference in the current task may indicate that older adults in our sample may be particularly high functioning, or the task adopted for the present study may be less sensitive to age-related cognitive changes. However, the present findings are consistent with other studies showing relatively preserved item recognition of visual scenes with advanced age (Spencer and Raz, 1995; Grady and Craik, 2000) and provide evidence of neural mechanisms supporting this relatively preserved performance of item recognition in older adults.

Because this study is cross-sectional, we cannot draw definitive causal inferences because the chronological order between changes

\section{References} 1844. CrossRef Medline Medline in regional activity, task-dependent and task-independent functional connectivity, and $\mathrm{A} \beta$ deposition are unknown. Longitudinal studies examining the sequences of these changes in the progression of $\mathrm{AD}$ pathology will shed light on the understanding of aging processes involving pathological changes and help in the early detection of people at risk of $\mathrm{AD}$ and development of prevention mechanisms.

\section{Conclusion}

Our results provide new insight into the nature of age and $\mathrm{A} \beta$-related changes in regional activity and functional connectivity during the encoding of new memories. At least two distinct neurocognitive mechanisms seem to be important in distinguishing episodic encoding in older adults compared with the young: a general age-related failure to engage brain regions crucial to encoding new information, such as MTL structures, and reduced taskindependent coupling across brain regions. These phenomena are accompanied by increased task-dependent functional connectivity contributing to preserved EM performance in $A \beta$-free older adults. In contrast, older adults with $\mathrm{A} \beta$ deposition fail to engage taskdependent functional coupling, while recruiting more local activity to perform EM encoding equivalently to older adults without A $\beta$ deposition. Longitudinal studies examining the temporal sequences between changes in regional activity, functional connectivity, and $\mathrm{A} \beta$ deposition will elucidate functional reorganization during the aging process in the face of brain pathology.

Achard S, Bullmore E (2007) Efficiency and cost of economical brain functional networks. PLoS Comput Biol 3:e17. CrossRef Medline

Agosta F, Vossel KA, Miller BL, Migliaccio R, Bonasera SJ, Filippi M, Boxer AL, Karydas A, Possin KL, Gorno-Tempini ML (2009) Apolipoprotein E epsilon4 is associated with disease-specific effects on brain atrophy in Alzheimer's disease and frontotemporal dementia. Proc Natl Acad Sci U S A 106:2018-2022. CrossRef Medline

Andrews-Hanna JR, Snyder AZ, Vincent JL, Lustig C, Head D, Raichle ME, Buckner RL (2007) Disruption of large-scale brain systems in advanced aging. Neuron 56:924-935. CrossRef Medline

Bangen KJ, Restom K, Liu TT, Jak AJ, Wierenga CE, Salmon DP, Bondi MW (2009) Differential age effects on cerebral blood flow and BOLD response to encoding: associations with cognition and stroke risk. Neurobiol Aging 30:1276-1287. CrossRef Medline

Bennett DA, Schneider JA, Arvanitakis Z, Kelly JF, Aggarwal NT, Shah RC, Wilson RS (2006) Neuropathology of older persons without cognitive impairment from two community-based studies. Neurology 66:1837-

Bero AW, Bauer AQ, Stewart FR, White BR, Cirrito JR, Raichle ME, Culver JP, Holtzman DM (2012) Bidirectional relationship between functional connectivity and amyloid-beta deposition in mouse brain. J Neurosci 32:4334-4340. CrossRef Medline

Bookheimer SY, Strojwas MH, Cohen MS, Saunders AM, Pericak-Vance MA, Mazziotta JC, Small GW (2000) Patterns of brain activation in people at risk for Alzheimer's disease. N Engl J Med 343:450-456. CrossRef 
Brett M, Anton J-L, Valabregue R, Poline J-B (2002) Region of interest analysis using an SPM toolbox Neuroimage 16.

Buckner RL, Snyder AZ, Shannon BJ, LaRossa G, Sachs R, Fotenos AF, Sheline YI, Klunk WE, Mathis CA, Morris JC, Mintun MA (2005) Molecular, structural, and functional characterization of Alzheimer's disease: evidence for a relationship between default activity, amyloid, and memory. J Neurosci 25:7709-7717. CrossRef Medline

Buckner RL, Andrews-Hanna JR, Schacter DL (2008) The brain's default network: anatomy, function, and relevance to disease. Ann N Y Acad Sci 1124:1-38. CrossRef Medline

Busche MA, Eichhoff G, Adelsberger H, Abramowski D, Wiederhold KH, Haass C, Staufenbiel M, Konnerth A, Garaschuk O (2008) Clusters of hyperactive neurons near amyloid plaques in a mouse model of Alzheimer's disease. Science 321:1686-1689. CrossRef Medline

Busche MA, Chen X, Henning HA, Reichwald J, Staufenbiel M, Sakmann B, Konnerth A (2012) Critical role of soluble amyloid-beta for early hippocampal hyperactivity in a mouse model of Alzheimer's disease. Proc Natl Acad Sci U S A 109:8740-8745. CrossRef Medline

Cabeza R (2002) Hemispheric asymmetry reduction in older adults: the HAROLD model. Psychol Aging 17:85-100. CrossRef Medline

Cabeza R, Grady CL, Nyberg L, McIntosh AR, Tulving E, Kapur S, Jennings JM, Houle S, Craik FI (1997) Age-related differences in neural activity during memory encoding and retrieval: a positron emission tomography study. J Neurosci 17:391-400. Medline

Celone KA, Calhoun VD, Dickerson BC, Atri A, Chua EF, Miller SL, DePeau K, Rentz DM, Selkoe DJ, Blacker D, Albert MS, Sperling RA (2006) Alterations in memory networks in mild cognitive impairment and Alzheimer's disease: an independent component analysis. J Neurosci 26:10222-10231. CrossRef Medline

Damoiseaux JS, Beckmann CF, Arigita EJ, Barkhof F, Scheltens P, Stam CJ, Smith SM, Rombouts SA (2008) Reduced resting-state brain activity in the "default network" in normal aging. Cereb Cortex 18:1856-1864. CrossRef Medline

Damoiseaux JS, Seeley WW, Zhou J, Shirer WR, Coppola G, Karydas A, Rosen HJ, Miller BL, Kramer JH, Greicius MD, Alzheimer's Disease Neuroimaging I (2012) Gender modulates the APOE epsilon4 effect in healthy older adults: convergent evidence from functional brain connectivity and spinal fluid tau levels. J Neurosci 32:8254-8262. CrossRef Medline

Daselaar SM, Fleck MS, Dobbins IG, Madden DJ, Cabeza R (2006) Effects of healthy aging on hippocampal and rhinal memory functions: an eventrelated fMRI study. Cereb Cortex 16:1771-1782. Medline

Daselaar SM, Prince SE, Dennis NA, Hayes SM, Kim H, Cabeza R (2009) Posterior midline and ventral parietal activity is associated with retrieval success and encoding failure. Front Hum Neurosci 3:13. Medline

Dennis NA, Cabeza R (2008) Neuroimaging of healthy cognitive aging. In: Handbook of aging and cognition, Ed 3 (Craik FIM, Salthouse TA, eds), pp 1-54. Mahwah, NJ: Erlbaum.

Dennis NA, Daselaar S, Cabeza R (2007) Effects of aging on transient and sustained successful memory encoding activity. Neurobiol Aging 28: 1749-1758. CrossRef Medline

Dennis NA, Hayes SM, Prince SE, Madden DJ, Huettel SA, Cabeza R (2008) Effects of aging on the neural correlates of successful item and source memory encoding. J Exp Psychol Learn Mem Cogn 34:791-808. CrossRef Medline

D’Esposito M, Deouell LY, Gazzaley A (2003) Alterations in the BOLD fMRI signal with ageing and disease: a challenge for neuroimaging. Nat Rev Neurosci 4:863-872. CrossRef Medline

Dickerson BC, Salat DH, Greve DN, Chua EF, Rand-Giovannetti E, Rentz DM, Bertram L, Mullin K, Tanzi RE, Blacker D, Albert MS, Sperling RA (2005) Increased hippocampal activation in mild cognitive impairment compared to normal aging and AD. Neurology 65:404-411. CrossRef Medline

Dickerson BC, Miller SL, Greve DN, Dale AM, Albert MS, Schacter DL, Sperling RA (2007) Prefrontal-hippocampal-fusiform activity during encoding predicts intraindividual differences in free recall ability: an event-related functional-anatomic MRI study. Hippocampus 17:10601070. CrossRef Medline

Duverne S, Habibi A, Rugg MD (2008) Regional specificity of age effects on the neural correlates of episodic retrieval. Neurobiol Aging 29:1902-1916. CrossRef Medline

Epstein R, Kanwisher N (1998) A cortical representation of the local visual environment. Nature 392:598-601. CrossRef Medline
Filippini N, MacIntosh BJ, Hough MG, Goodwin GM, Frisoni GB, Smith SM, Matthews PM, Beckmann CF, Mackay CE (2009) Distinct patterns of brain activity in young carriers of the APOE-epsilon4 allele. Proc Natl Acad Sci U S A 106:7209-7214. CrossRef Medline

Fleisher AS, Podraza KM, Bangen KJ, Taylor C, Sherzai A, Sidhar K, Liu TT, Dale AM, Buxton RB (2009) Cerebral perfusion and oxygenation differences in Alzheimer's disease risk. Neurobiol Aging 30:1737-1748. CrossRef Medline

Friston KJ, Ashburner J, Frith CD, Poline JB, Heather JD, Frackowiak RSJ (1995) Spatial registration and normalization of images. Hum Brain Mapp 3:165-189. CrossRef

Friston KJ, Williams S, Howard R, Frackowiak RS, Turner R (1996) Movement-related effects in fMRI time-series. Magn Reson Med 35:346355. CrossRef Medline

Friston KJ, Buechel C, Fink GR, Morris J, Rolls E, Dolan RJ (1997) Psychophysiological and modulatory interactions in neuroimaging. Neuroimage 6:218-229. CrossRef Medline

Gazzaley A, Rissman J, Cooney J, Rutman A, Seibert T, Clapp W, D’Esposito M (2007) Functional interactions between prefrontal and visual association cortex contribute to top-down modulation of visual processing. Cereb Cortex 17 [Suppl 1]:i125-i135. CrossRef Medline

Gitelman DR, Penny WD, Ashburner J, Friston KJ (2003) Modeling regional and psychophysiologic interactions in fMRI: the importance of hemodynamic deconvolution. Neuroimage 19:200-207. CrossRef Medline

Grady C (2012) The cognitive neuroscience of ageing. Nat Rev Neurosci 13:491-505. CrossRef Medline

Grady CL, Craik FI (2000) Changes in memory processing with age. Curr Opin Neurobiol 10:224-231. CrossRef Medline

Grady CL, McIntosh AR, Horwitz B, Maisog JM, Ungerleider LG, Mentis MJ, Pietrini P, Schapiro MB, Haxby JV (1995) Age-related reductions in human recognition memory due to impaired encoding. Science 269:218221. CrossRef Medline

Grady CL, McIntosh AR, Rajah MN, Beig S, Craik FI (1999) The effects of age on the neural correlates of episodic encoding. Cereb Cortex 9:805814. CrossRef Medline

Grady CL, McIntosh AR, Craik FI (2003) Age-related differences in the functional connectivity of the hippocampus during memory encoding. Hippocampus 13:572-586. CrossRef Medline

Grady CL, McIntosh AR, Craik FI (2005) Task-related activity in prefrontal cortex and its relation to recognition memory performance in young and old adults. Neuropsychologia 43:1466-1481. CrossRef Medline

Grady CL, Protzner AB, Kovacevic N, Strother SC, Afshin-Pour B, Wojtowicz M, Anderson JA, Churchill N, McIntosh AR (2010) A multivariate analysis of age-related differences in default mode and task-positive networks across multiple cognitive domains. Cereb Cortex 20:1432-1447. CrossRef Medline

Greicius MD, Srivastava G, Reiss AL, Menon V (2004) Default-mode network activity distinguishes Alzheimer's disease from healthy aging: evidence from functional MRI. Proc Natl Acad Sci U S A 101:4637-4642. CrossRef Medline

Gutchess AH, Welsh RC, Hedden T, Bangert A, Minear M, Liu LL, Park DC (2005) Aging and the neural correlates of successful picture encoding: frontal activations compensate for decreased medial-temporal activity. J Cogn Neurosci 17:84-96. CrossRef Medline

Hedden T, Van Dijk KR, Becker JA, Mehta A, Sperling RA, Johnson KA, Buckner RL (2009) Disruption of functional connectivity in clinically normal older adults harboring amyloid burden. J Neurosci 29:1268612694. CrossRef Medline

Iadecola C (2004) Neurovascular regulation in the normal brain and in Alzheimer's disease. Nat Rev Neurosci 5:347-360. CrossRef Medline

Jagust WJ, Landau SM, Alzheimer's Disease Neuroimaging Initiative (2012) Apolipoprotein E, not fibrillar beta-amyloid, reduces cerebral glucose metabolism in normal aging. J Neurosci 32:18227-18233. CrossRef Medline

Logan J, Fowler JS, Volkow ND, Wang GJ, Ding YS, Alexoff DL (1996) Distribution volume ratios without blood sampling from graphical analysis of PET data. J Cereb Blood Flow Metab 16:834-840. Medline

Lustig C, Snyder AZ, Bhakta M, O’Brien KC, McAvoy M, Raichle ME, Morris JC, Buckner RL (2003) Functional deactivations: change with age and dementia of the Alzheimer type. Proc Natl Acad Sci U S A 100:1450414509. CrossRef Medline 
Mathis CA, Wang Y, Holt DP, Huang GF, Debnath ML, Klunk WE (2003) Synthesis and evaluation of 11C-labeled 6-substituted 2-arylbenzothiazoles as amyloid imaging agents. J Med Chem 46:2740-2754. CrossRef Medline

Mintun MA, Larossa GN, Sheline YI, Dence CS, Lee SY, Mach RH, Klunk WE, Mathis CA, DeKosky ST, Morris JC (2006) [11C]PIB in a nondemented population: potential antecedent marker of Alzheimer disease. Neurology 67:446-452. CrossRef Medline

Morcom AM, Good CD, Frackowiak RS, Rugg MD (2003) Age effects on the neural correlates of successful memory encoding. Brain 126:213-229. CrossRef Medline

Mormino EC, Brandel MG, Madison CM, Marks S, Baker SL, Jagust WJ (2012a) Abeta Deposition in aging is associated with increases in brain activation during successful memory encoding. Cereb Cortex 22:18131823. CrossRef Medline

Mormino EC, Brandel MG, Madison CM, Rabinovici GD, Marks S, Baker SL, Jagust WJ (2012b) Not quite PIB-positive, not quite PIB-negative: slight PIB elevations in elderly normal control subjects are biologically relevant. Neuroimage 59:1152-1160. CrossRef Medline

Palop JJ, Mucke L (2010) Amyloid-beta-induced neuronal dysfunction in Alzheimer's disease: from synapses toward neural networks. Nat Neurosci 13:812-818. CrossRef Medline

Perrin RJ, Fagan AM, Holtzman DM (2009) Multimodal techniques for diagnosis and prognosis of Alzheimer's disease. Nature 461:916-922. CrossRef Medline

Power JD, Barnes KA, Snyder AZ, Schlaggar BL, Petersen SE (2012) Spurious but systematic correlations in functional connectivity MRI networks arise from subject motion. Neuroimage 59:2142-2154. CrossRef Medline

Price JC, Klunk WE, Lopresti BJ, Lu X, Hoge JA, Ziolko SK, Holt DP, Meltzer CC, DeKosky ST, Mathis CA (2005) Kinetic modeling of amyloid binding in humans using PET imaging and Pittsburgh Compound-B. J Cereb Blood Flow Metab 25:1528-1547. CrossRef Medline

Prince SE, Dennis NA, Cabeza R (2009) Encoding and retrieving faces and places: distinguishing process- and stimulus-specific differences in brain activity. Neuropsychologia 47:2282-2289. CrossRef Medline

Roberson ED, Halabisky B, Yoo JW, Yao J, Chin J, Yan F, Wu T, Hamto P, Devidze N, Yu GQ, Palop JJ, Noebels JL, Mucke L (2011) Amyloid-beta/ Fyn-induced synaptic, network, and cognitive impairments depend on tau levels in multiple mouse models of Alzheimer's disease. J Neurosci 31:700-711. CrossRef Medline

Sheline YI, Raichle ME, Snyder AZ, Morris JC, Head D, Wang S, Mintun MA (2010a) Amyloid plaques disrupt resting state default mode network connectivity in cognitively normal elderly. Biol Psychiatry 67:584-587. CrossRef Medline

Sheline YI, Morris JC, Snyder AZ, Price JL, Yan Z, D’Angelo G, Liu C, Dixit S, Benzinger T, Fagan A, Goate A, Mintun MA (2010b) APOE4 allele disrupts resting state fMRI connectivity in the absence of amyloid plaques or decreased CSF Abeta42. J Neurosci 30:17035-17040. CrossRef Medline

Simons JS, Spiers HJ (2003) Prefrontal and medial temporal lobe interac- tions in long-term memory. Nat Rev Neurosci 4:637-648. CrossRef Medline

Snodgrass JG, Corwin J (1988) Pragmatics of measuring recognition memory: applications to dementia and amnesia. J Exp Psychol Gen 117:34-50. CrossRef Medline

Sorg C, Riedl V, Mühlau M, Calhoun VD, Eichele T, Läer L, Drzezga A, Förstl H, Kurz A, Zimmer C, Wohlschläger AM (2007) Selective changes of resting-state networks in individuals at risk for Alzheimer's disease. Proc Natl Acad Sci U S A 104:18760-18765. CrossRef Medline

Spencer WD, Raz N (1995) Differential effects of aging on memory for content and context: a meta-analysis. Psychol Aging 10:527-539. CrossRef Medline

Sperling R, Chua E, Cocchiarella A, Rand-Giovannetti E, Poldrack R, Schacter DL, Albert M (2003) Putting names to faces: successful encoding of associative memories activates the anterior hippocampal formation. Neuroimage 20:1400-1410. CrossRef Medline

Sperling RA, Laviolette PS, O'Keefe K, O’Brien J, Rentz DM, Pihlajamaki M, Marshall G, Hyman BT, Selkoe DJ, Hedden T, Buckner RL, Becker JA, Johnson KA (2009) Amyloid deposition is associated with impaired default network function in older persons without dementia. Neuron 63 : 178-188. CrossRef Medline

Spreng RN, Wojtowicz M, Grady CL (2010) Reliable differences in brain activity between young and old adults: a quantitative meta-analysis across multiple cognitive domains. Neurosci Biobehav Rev 34:1178-1194. CrossRef Medline

Tzourio-Mazoyer N, Landeau B, Papathanassiou D, Crivello F, Etard O, Delcroix N, Mazoyer B, Joliot M (2002) Automated anatomical labeling of activations in SPM using a macroscopic anatomical parcellation of the MNI MRI single-subject brain. Neuroimage 15:273-289. CrossRef Medline

Van Dijk KR, Sabuncu MR, Buckner RL (2012) The influence of head motion on intrinsic functional connectivity MRI. Neuroimage 59:431-438. CrossRef Medline

Vannini P, Hedden T, Huijbers W, Ward A, Johnson KA, Sperling RA (2013) The ups and downs of the posteromedial cortex: age- and amyloid-related functional alterations of the encoding/retrieval flip in cognitively normal older adults. Cereb Cortex 23:1317-1328. CrossRef Medline

Vincent JL, Kahn I, Snyder AZ, Raichle ME, Buckner RL (2008) Evidence for a frontoparietal control system revealed by intrinsic functional connectivity. J Neurophysiol 100:3328-3342. CrossRef Medline

Wagner AD, Shannon BJ, Kahn I, Buckner RL (2005) Parietal lobe contributions to episodic memory retrieval. Trends Cogn Sci 9:445-453. CrossRef Medline

Westlye ET, Lundervold A, Rootwelt H, Lundervold AJ, Westlye LT (2011) Increased hippocampal default mode synchronization during rest in middle-aged and elderly APOE epsilon4 carriers: relationships with memory performance. J Neurosci 31:7775-7783. CrossRef Medline

Wilke M (2012) An alternative approach toward assessing and accounting for individual motion in fMRI timeseries. Neuroimage 59:2062-2072. CrossRef Medline 